\title{
La solidaridad. El lenguaje de la sensibilidad moral
}

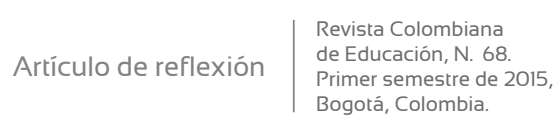

Bogotá, Colombia.

\author{
//Solidarity. The Language \\ of Moral Sensitivity
}

//A solidariedade. A linguagem da
sensibilidade moral

Yicel Nayrobis Giraldo*

Alexander Ruiz Silva**

\begin{abstract}
Directora de la Maestría en Educación y Desarrollo Humano de la Universidad de Manizales - Cinde, sede Regional Medellín. Investigadora del Grupo Educación y Pedagogía: saberes, imaginarios e intersubjetividades. Candidata a Doctora en Ciencias Sociales, Niñez y Juventud de la Universidad de Manizales - Fundación Centro Internacional de Educación y Desarrollo Humano, Cinde. Magíster en Educación y Desarrollo Humano. yngiraldo@gmail.com / ygiraldo@cinde.org.co Profesor Titular de la Universidad Pedagógica Nacional, Doctor en Ciencias Sociales de Flacso Argentina. Coordinador del Doctorado en Educación DIE - UPN. Codirector del Grupo de Investigación Moralia. alexruizsilva@yahoo.com / aruiz@pedagogica.edu.co
\end{abstract}

\section{Resumen}

El texto presenta una revisión, caracterización y discusión del concepto de solidaridad en el ámbito de la filosofía práctica, desde las perspectivas de Richard Rorty, Karl-Otto Apel y Axel Honneth. Se pretende, de este modo, tematizar sus alcances y limitaciones en dinámicas y procesos sociales que suelen obtener legitimidad de orientaciones morales fundamentadas en principios de justicia e igualdad. Aunque se trata de enfoques distintos y, en algunos casos, diametralmente opuestos, que apuntan, bien a la ampliación práctica del círculo ético (Rorty), bien a la fundación normativa de la responsabilidad solidaria (Apel), bien al reconocimiento de las particularidades para la construcción de proyectos comunes (Honneth), se puede reconocer un punto de partida común en torno a la pregunta y la preocupación por la situación del otro, especialmente, de quien sufre, de aquel que nos conmina a un sentido de la responsabilidad y que nos demanda reconocimiento y valoración social de su singularidad. En consideración de las múltiples diferencias y coincidencias que se puedan sostener respecto del concepto en cuestión, aquí se afirma que el mismo permite construir o reconstruir el vínculo ético-político entre los sujetos, sobre la base de relaciones -en algunos casos asimétricas, en otros simétricas- en las que prima la búsqueda de la justicia en relación directa con el aminoramiento del sufrimiento humano.

\section{Abstract}

This text presents a review, characterization and discussion of the concept of solidarity in the field of practical philosophy, from the perspectives of Richard Rorty, Karl-Otto Apel and Axel Honneth. It attempts to materialize its scope and limitations in dynamic and social processes often validated through moral inclinations based on principles of justice and equality. Although dealing with distinct -and, in some cases, diametrically conflicting- approaches aiming at the practical extension of the ethical field (Rorty), at the regulatory foundation of joint responsibility (Apel), at the acknowledgment of peculiarities for the

\section{Palabras clave}

Solidaridad, responsabilidad, reconocimiento, sufrimiento, justicia.

\section{Keywords}

Solidarity, responsibility, recognition, suffering, justice.

\section{Palavras chave}

Solidariedade, Responsabilidade, Reconhecimento, Sofrimento, Justiça. 
construction of common projects (Honneth), a common starting point may be identified around the question and concern for the situation of the other, especially those who suffer, those compelling us to develop a sense of responsibility, those who demand from us recognition and social worth of their uniqueness. In consideration of the multiple differences and coincidences which may be stated concerning the concept in question, it is hereby stated that the very same concept allows building or rebuilding the ethical-political bond among subjects, on the basis of relations -sometimes asymmetrical, sometimes symmetrical-where the search for justice, in direct relation with the reduction of human suffering, plays a prevailing role.

\section{Resumo}

O texto apresenta uma revisão, caracterização e discussão do conceito de solidariedade no âmbito da filosofia prática, desde as perspectivas de Richard Rorty, Karl-Otto Apel e Axel Honneth. Se pretende, deste modo, tematizar seus alcances e limitações em dinâmicas e processos sociais que geralmente optem legitimidade de orientações morais fundamentadas em princípios de justiça e igualdade. Embora tratasse de enfoques distintos e, em alguns casos, diametralmente opostos, que apontam, bem à ampliação pratica do circulo ético (Rorty), bem à fundação normativa da responsabilidade solidaria (Apel), bem ao reconhecimento das particularidades para a construção de projetos comuns (Honneth), pode-se reconhecer um ponto de partida comum em volta à pergunta e a preocupação pela situação do outro, especialmente, de quem sofre, daquele que nós leva a um sentido da responsabilidade e que demanda em nós reconhecimento e valoração social da sua singularidade. Em consideração das múltiples diferenças e coincidências que possam manter respeito do conceito em que estão, aqui se afirma que o mesmo permite construir o reconstruir o vinculo ético-político entre os sujeitos, sob a base de relações -em alguns casos assimétrica, em outros simétrica- nas que o mais importante é a procura da justiça em relação direta com a diminuição do sofrimento humano.

El concepto de solidaridad no ha tenido en la filosofía práctica, ni en las ciencias sociales, ni en el campo de la educación, en general, un importante desarrollo en comparación, por ejemplo, con los de justicia, libertad o igualdad. Esto es comprensible si se piensa, por ejemplo, en la poca o nula plausibilidad que tendría su uso como fundamento de una eventual teoría moral. Las decisiones y las acciones solidarias requieren de orientaciones de vida buena o de justicia que las articulen, las justifiquen, en suma, que les otorguen sentido moral.

En contraste con esta orientación, es necesario reconocer formas de ejercicio negativo de la solidaridad como la denominada solidaridad en la falta o la cooperación pasiva o activa con quien intencionalmente hace daño a otros, algo que fácilmente 
se puede constatar en el accionar de los grupos criminales, en el maltrato escolar y de forma menos extrema en la aprobación social del incumplimiento de normas injustas.

Daños a los otros, de distinta intensidad y de nefastas consecuencias, se basan en formas de solidaridad que consideramos irracionales, injustas, en suma: inmorales. Así, nos podemos sentir conminados a actuar en contra $\mathrm{o}$ al menos a no avalar una acción que ha sido concertada solidariamente, en condiciones de relativa simetría, si juzgamos que esta acción trae perjuicio a otras personas. Pero, ipodemos pensar, no obstante, en un significado de la solidaridad que trascienda la simple motivación moral?, ¿es posible que en medio de la diversidad de perspectivas sobre la solidaridad se pueda identificar un sentido común de la justicia que opere como horizonte moral para la acción solidaria?

Para situarnos frente a estos interrogantes, mucho más que para responderlos, hemos echado mano de autores ubicados en diferentes perspectivas teóricas: Richard Rorty (giro pragmático), Karl-Otto Apel (giro comunicativo) y Axel Honneth (teoría crítica), quienes proponen diversos, e incluso divergentes abordajes de la solidaridad e introducen interesantes matices para comprender su ejercicio en la sociedad actual. De este modo, esbozaremos, primero, algunos planteamientos que permitan la comprensión general de cada una de estas perspectivas (apartados 1,2 y 3 ), sin pretender agotar las múltiples opciones de lectura que de allí puedan derivarse, para, finalmente, destacar algunos elementos susceptibles de articulación o relieve, que permitan bien precisar, bien delimitar, el concepto en cuestión y reconocer nuevos retos en relación con su estudio tanto en el campo de las ciencias sociales como en el de la educación (apartado 4).

\section{La solidaridad como respuesta al sufrimiento humano y como forma de evitar el daño}

En una ampliación y profundización de algunas convicciones compartidas por pensadores pragmatistas como James y Dewey, Richard Rorty sugiere un desplazamiento del interés filosófico de la búsqueda de la objetividad hacia la búsqueda de la solidaridad, en la medida en que la contingencia humana: "Implica cambiar el 'sitial de la autoridad' que ha de guiar la investigación intelectual y orientar el progreso social" (Figueroa, 2007, p. 155). Este desplazamiento sintetiza la sustitución de una objetividad como representación exacta por una objetividad intersubjetiva, lo que en palabras del mismo Rorty consiste en:
... tomar a los demás se- res humanos en serio $y$ no tomarse ninguna otra cosa tan en serio como a ellos. Para los pragmatis- tas, resulta que podemos tomarnos unos a otros 
realmente muy en serio sin tomar en serio para nada la naturaleza intrínseca de la realidad (Rorty, 2000, p. 114).

De este modo, el sentido de la filosofía no debería residir en la búsqueda de la verdad o de criterios cartesianos de certeza, sino en un anhelo de justicia en relación con la expansión de la solidaridad. A juicio de Rorty, el pensamiento filosófico debe dar un giro ético y debería asumir como tarea principal: "Clarificar las ideas en relación con las batallas sociales y morales de su propio tiempo" (Dewey, citado por Rorty, 2000, p. 302). En este sentido, cabe pensar que una de las principales batallas que debe afrontar el pensamiento filosófico actual consiste en:

... desarrollar una imaginación ética que opere como fuerza humanizadora y nutriente de un sentido inclusivo de justicia. Se hace necesaria la disposición solidaria que nos prepare para atisbar los cambios que nos puedan conducir a una disminución de la desigualdad en el mundo (Figueroa, 2007, p. 196).

En el marco de un proyecto de esta índole resulta fundamental la figura del ironista liberal. El ironista es aquella persona que reconoce la contingencia de sus creencias y sus deseos. En tal sentido, ha de reunir tres condiciones fundamentales, a saber: 1) debe mantener dudas radicales y permanentes sobre el léxico que usa cotidianamente, pues en este han incidido otros léxicos, otros lenguajes, otras formas de vida; 2) debe advertir que el argumento formulado con y desde su léxico actual no eliminará sus dudas sobre aspectos importantes de la vida; y 3) debe reconocer que su léxico actual no se encuentra más cerca de la realidad que el de los otros, de tal modo que nunca se podrá tener acceso a un metaléxico neutral y universal, por tanto, solo puede acceder a "un modo de enfrentar lo nuevo con lo viejo" (Rorty, 2001, p. 91). Por eso, el ironista:

... pasa su tiempo preocupado por la posibilidad de haber sido iniciado en la tribu errónea, de haber aprendido el juego de lenguaje equivocado. Le inquieta que el proceso de socialización que le convirtió en ser humano al darle un lenguaje pueda haberle dado el lenguaje equivocado y haberlo convertido con ello en la especie errónea de ser humano (Rorty, 2001, p. 93).

Ahora bien, la figura del ironista recibe el calificativo de liberal en la medida en que expresa abiertamente que "la crueldad 
es la peor cosa que se puede hacer contra la libertad de los otros" (Judith Shklar, citada por Rorty, 2001, p. 92). Así, ostenta una amplia consciencia de historicidad y nominalismo, desde donde concibe a los léxicos últimos como logros poéticos. Desde tales léxicos pretende hacer de la descripción detallada de cómo son las personas y sobre los modos como convencionalmente nos comprendemos, nos interpretamos y nos narramos. Los ironistas liberales son aquellas personas que "entre sus deseos imposibles de fundamentar incluyen sus propias esperanzas de que el sufrimiento ha de disminuir, que la humillación por seres humanos por obra de otros seres humanos ha de cesar" (Rorty, 2001, p. 17).

Desde este marco comprensivo, la solidaridad es:

La capacidad imaginativa de ver a los extraños como compañeros en el sufrimiento. La solidaridad no se descubre, sino que se crea, por medio de la reflexión. Se crea incrementando nuestra sensibilidad a los detalles particulares del dolor y de la humillación de seres humanos distintos, desconocidos para nosotros (Rorty, 2001, p. 18).

De esto modo, la solidaridad expresa algo que hemos desarrollado en cada uno de nosotros, nos permite precisar nuestro referente moral (criterios de justicia) y ampliar nuestro círculo ético (relaciones interpersonales reguladas normativamente), máxime si se considera que la crueldad es lo peor que puede existir en el mundo.

Ahora bien, la disposición a ampliar el sentido moral de la solidaridad depende de que asumamos que "aquel con el que expresamos ser solidario, es 'uno de nosotros', giro en el que 'nosotros' significa algo más restringido y más local que la raza humana" (Rorty, 2001, p. 209). La posibilidad de llegar a compartir la certeza del sufrimiento se convierte así en un componente clave de la solidaridad. Su invocación no representa, ni mucho menos, un intento de hallar la esencia de la naturaleza humana desde donde exclusivamente se justifiquen sentimientos y actitudes solidarias hacia otras personas. Realmente, de lo que se trata es de algo más restringido y local, de aquello que enlaza al ser humano concreto, real, particular que sufre, que padece dolor, daño.

Cuando se es capaz de asumir al otro como uno de nosotros es porque se tiene la certeza de compartir con él un peligro común, hecho que podría ser considerado condición necesaria, aunque no suficiente, para el incremento social de la solidaridad. Llegar a compartir esta certeza frente al sufrimiento presupone una puesta en escena de criterios de valoración moral: el sujeto juzga la situación del otro como sufrimiento, innecesario, injusto, y halla en esta situación un riesgo que 
lo alerta frente a la posibilidad de llegar a padecerlo. La persona, en cuanto sujeto moral, percibe que puede llegar a "ser algo que puede ser humillado" (Rorty, 2001 p. 109), así que el peligro consiste en suponer la posibilidad de la experiencia del dolor y de la humillación, en sí mismo, en cualquiera.

Vale enfatizar que para Rorty la solidaridad no se descubre o no se halla oculta en cada uno de nosotros, acaso como parte de nuestra dotación genética, biológica, inmanente o racional. Por tanto, la historicidad del ser humano y del mundo son condiciones fundamentales para replantear y reformular las concepciones tradicionales de la solidaridad, que no son otra cosa que la expresión de una "verdad superior a nosotros", que se justifica, ya sea en la existencia de Dios o en los límites impuestos por la razón moderna. En otras palabras, Rorty rechaza vehementemente la noción de solidaridad entendida como una naturaleza ahistórica, universal y absoluta que poco tiene que decirnos sobre nuestra propia cotidianidad.

De modo complementario, la solidaridad se incrementa frente a los detalles particulares del dolor y de la humillación, lo cual significa aumento de la sensibilidad. Esto, a su vez, supone que hay algo que resuena en nosotros frente a la evidencia de algo que nos es común y que vemos en otros seres humanos. No basta con exponer las "razones" que deberían conducirnos a actuar a favor del otro, solo se requiere sentirse motivado e implicado en algo con respecto a alguien para actuar efectivamente a favor de él; lo cual significa sentirse responsable moralmente de reconocer la evidencia de lo que nos es común y actuar en consecuencia. Así pues, la solidaridad tiene menos que ver con la racionalidad de los argumentos que hallemos a favor de actuar solidariamente y más con la sensibilidad de compartir con otros el sufrimiento y el rechazo a la crueldad, en las diferentes formas que podríamos padecerla.

Ahora bien, dado que la solidaridad expresa una sensibilidad moral que puede incrementarse por la capacidad imaginativa de identificarnos con personas distintas a nosotros, esto significa que dicha sensibilidad puede desarrollarse, cultivarse y educarse: es susceptible de "fortalecerse y ensancharse tanto como de experimentar debilitamiento y reducción" (Figueroa, 2007, p. 169). Al respecto, Rorty atribuye al contacto directo, abierto y sensible con el arte, con la obra literaria, en particular con la novela, un papel fundamental en el incremento de dicha sensibilidad, pues ella representa la diversidad de puntos 
de vista, la pluralidad de miradas y de relatos respecto de un mismo acontecimiento, la renuncia a privilegiar una narración y a presentarla como única y verdadera, en menoscabo de otras. La novela es, aquí, el territorio de las posibilidades y de las múltiples perspectivas, en ella radica un potencial especialmente valorado para la construcción de una sociedad que pueda interrogarse menos por "la naturaleza humana" y más por lo que podríamos hacer para convivir pacíficamente a pesar de nuestras radicales diferencias ${ }^{1}$.

En la novela -en la literatura- se halla un permanente y vívido recordatorio del sentido de lo humano, de la valoración de aquello que nos hace realmente humanos, en el contacto que establecemos con el otro. De esta manera, la literatura y no la televisión, por ejemplo, estimularía la imaginación narrativa como imaginación ética: al gestar en la fantasía y en la ficción la realidad es entendida no solo como fatalidad, también es posibilidad, acontecimiento y novedad ${ }^{2}$.

1 En este punto, encontramos afinidad con los planteamientos de Nussbaum acerca de la imaginación estimulada por la literatura, como un "ingrediente esencial de una postura ética que nos insta a interesarnos en el bienestar de personas cuyas vidas están distante de las nuestras" (Nussbaum, 1997, p. 18). Esta imaginación nos permitiría insertarnos en dinámicas múltiples y plurales de reconocimientos y aperturas a la experiencia humana para el desarrollo de aquellas motivaciones que nos impulsarían a modificar las condiciones adversas y precarias del que sufre o del que es víctima de crueldad o injusticia.

2 La imaginación narrativa entraña la capacidad de pensar y sentir cómo sería estar en el lugar de otra persona reconociendo sus sentimientos,
La conciencia de la solidaridad, desde el lugar de la vulnerabilidad de un sujeto que encarna el sufrimiento, como algo común en lo diverso permite la activación de una disposición moral que impide
Mantenernos indiferentes frente al sufrimiento del otro, en el reconocimien- to de que nuestra concu- rrencia práctica puede marcar un cambio efec- tivo en la suerte que ese otro vive, sea este parte o no de mi grupo, com- parta o no mi raza, mi re- ligión o mi nacionalidad (Figueroa, 2007, p. 171).

En consecuencia, la solidaridad depende de las similitudes y diferencias que consideramos más notorias entre seres humanos diversos y esta condición de notoriedad se establece en función de un léxico último históricamente contingente. Emerge, por tanto, en y a propósito de la diferencia más que en la similitud y se asocia "a la capacidad de ver las diferencias entre unos y otros en función de un nosotros más

deseos y expectativas (Nussbaum, 2011). Esta capacidad de pensar y de sentir supone la puesta en práctica de un interés genuino por los demás, el cual está asociado al cumplimiento de tres requisitos previos: el primero está relacionado con un cierto grado de competencia práctica, por cuanto el niño y la niña comprende que no es necesario esclavizar al otro para satisfacer sus necesidades; el segundo tiene que ver con el reconocimiento de un mundo que está habitado por otros, los cuales tienen sus propias vidas y necesidades y tienen el derecho de satisfacerlas; y el tercero está ligado a "la capacidad de imaginar cómo puede ser la experiencia del otro" (Nussbaum, 2011, p. 134). 
extenso" (Figueroa, 2007, p. 173). De ahí que aquello que nos parece más notorio tendría que impulsarnos a actuar para mitigar el sufrimiento del otro, más allá de que este pertenezca o no a nuestro grupo de referencia más cercano.

Desde esta postura, lo que nos mueve con mayor fuerza a la solidaridad es el reconocimiento de que el otro es susceptible de sufrir, al igual que yo, un dolor que rebasa lo meramente físico. Este sufrimiento o dolor no es algo lingüístico. De ahí que las víctimas de la crueldad no puedan expresar lo padecido; el trato al que han sido expuestos les ha arrebatado el lenguaje, por ello no logran encontrar palabras con nuevos sentidos y significados para narrar, para re-describir su experiencia. Así pues, el dolor no es algo lingüístico, aunque muchas veces sea necesario recurrir al lenguaje para superarlo, esto es, para re-describirlo como experiencia y hacerlo parte de una historia común. En esto se basa Rorty para sostener una distinción fundamental entre el dolor y la humillación. El dolor es aquello que nos vincula y que compartimos con los animales. Por su parte, la humillación va más allá del sufrimiento puramente físico y solo el ser humano puede percibirla y experimentarla. La humillación puede, así, adoptar distintas formas: maltrato psicológico-corporal, desvaloración personal, falta de reconocimiento o desconocimiento efectivo de la condición de persona.

En este sentido, la solidaridad no solo implica la relación actual o potencial que establecemos con los extraños para hacerlos parte de nosotros, también articula la cuestión de compartir una esperanza egoísta común: "La esperanza de que el mundo de uno -las pequeñas cosas en torno de las cuales uno ha tejido el propio léxico último- no será destruido" (Rorty, 2001, p. 110, énfasis del original). Tal idea de la solidaridad soporta la expresión de un egoísmo común que no tendría por qué escandalizarnos. Quizá por eso Rorty asegura que la solidaridad "no es cosa que dependa de la participación en una verdad común o en una meta común" (2001, p. 110), sino que reside en la tendencia egoísta y particular que hace causa común con quienes tienen el mismo anhelo: evitar que el mundo que hemos construido desaparezca.

La solidaridad es, entonces y a la vez, disposición moral y praxis política desde la cual se promueve el desarrollo de las potencialidades de todos y cada uno de los seres humanos, en tal sentido, enlaza la idea de justicia, se trata, en suma, de 
Un acto voluntario dirigido a la consecución de una vida colectiva buena y justa, y supone la creación de un orden social, desde principios igualitarios, que permita materializar el contenido de la libertad positiva. Por ello, la libertad y la solidaridad funcionan como condiciones recíprocas, necesarias para sus respectivos desarrollos (Astorga y Kohn, 2001, p. 140).

De modo complementario, es importante señalar que las acciones solidarias, para serlo, en sentido propio, exigen la asunción de los intereses de quien sufre, en el espacio público, en el que los miembros de una sociedad se comprometen con un proyecto social que pone en relación lo colectivamente concertado con lo egoístamente anhelado (Astorga y Kohn, 2001). De esta manera, la política se entiende como "el modo práctico de dar forma social al impulso ético" (Mardones, 1994, p. 44). El ejercicio político de la solidaridad se plantea, así, como una alternativa a la injusticia, a todas aquellas condiciones y situaciones que provocan sufrimiento y humillación a los seres humanos, en los tiempos actuales. Su orientación positiva deberá, en principio, prepararnos para:

\begin{abstract}
[...] atisbar los cambios que nos pueden conducir a una disminución de la desigualdad en el mundo [...] Si la solidaridad refleja la esencia de la ética es porque nace de la ineludible convicción de que la suerte de otros depende de lo que hacemos o dejamos de hacer. La solidaridad no reemplaza la justicia, pero la compensa y complementa, le plantea una exigencia de perfeccionamiento, la impulsa a su profundización, le muestra un horizonte, le indica una dirección (Figueroa, 2007, p. 196).
\end{abstract}

De otro lado, la solidaridad requiere de imaginación ética, desde donde se proponen horizontes de sentido a la acción humana. La imaginación se asume acá como el lugar de lo posible, de lo que todavíano-es pero que podría llegar a ser. Si en algo puede aportar la filosofía a la sociedad moderna, según el planteamiento que venimos exponiendo, es a la re-creación de nuevos léxicos últimos, de re-descripciones para "ensanchar el ámbito de lo posible" (Rorty, 2000, p. 345).

El papel de la imaginación no es otro aquí que el de despertar en nosotros el sentido de lo prácticamente posible, de lo que

Merece, a través de nues-
tra acción, pasar de la 
mera posibilidad a la realidad efectiva. Se trata de una imaginación que no rehúye al poder, sino todo lo contrario, que está animada por la pretensión de habitar y nutrir la esfera política, de levantar en ella frentes diversos para la acción, el cambio y la experimentación (Figueroa, 2007, p. 194).

Frente a las aspiraciones orientadas al progreso moral, en las últimas páginas de Contingencia, ironía y solidaridad, Rorty enfatiza:

[...] lo que se considere un ser humano como es debido es algo relativo a la circunstancia histórica, algo que depende de un acuerdo transitorio acerca de qué actitudes son normales y qué prácticas son justas e injustas. No obstante, en épocas como la de Auschwitz, en las que la historia produce un cataclismo, y las instituciones y las normas de conducta tradicionales se desploman, deseamos algo que se encuentre más allá de la historia y de las instituciones. ¿Qué otra cosa puede ser, si no la solidaridad humana, nuestro reconocimiento de una humanidad que nos es común? (Rorty, 2001, p. 207).

Ahora bien, la idea de progreso moral que se insinúa en estas líneas no está asociada a la convergencia de opiniones humanas sobre lo que a todos conviene, sino más bien al incremento de la capacidad

Para ver como moralmente irrelevantes un número creciente de diferencias entre los individuos. Tal capacidad -la de ver las diferencias que presentan las personas en cuanto a su religión, nacionalidad, género, raza, estatus económico, etc., como irrelevantes para la posibilidad de cooperar con ellas en beneficio mutuo y para la necesidad de aliviar su sufrimiento- han aumentado considerablemente a partir de la llustración (Rorty, 2000, p. 24).

En este sentido, el avance moral de una sociedad solo podría ser el resultado de una dinámica social y política inclusiva, solidaria, desde donde se dé una especie de ampliación del sentido del nosotros. Dicha apertura y ampliación está en directa correspondencia con la identificación imaginativa de las personas frente a los detalles particulares de dolor y humiIlación que pueden padecer los demás. Así: "Cada vez con mayor claridad las diferencias tradicionales (de tribu, de religión, de 
raza, de costumbres, y las demás de la misma especie) carecen de importancia cuando se las compara con las similitudes referentes al dolor y la humillación" (Rorty, 2001, p. 210).

Son varios los asuntos que podemos destacar de este enfoque. Quisiéramos, por ahora, mencionar tres:

1) La capacidad imaginativa orientada hacia la inclusión del extraño, del otro, como "uno de nosotros". Pero, ¿qué implica esta ampliación? Exige, en principio, sobreponerse a las diferencias culturales, étnicas, religiosas, políticas, sociales, sexuales, entre otras; ser capaces de suspender los juicios y obstáculos comunicativos que tales diferencias pueden anteponer a la acción individual, especialmente ante situaciones específicas de dolor y humillación. Por ello, la solidaridad se entiende como una disposición moral ante cualquier persona en condición de vulnerabilidad, sin importar de quién se trate o de dónde provenga. Es, en suma, una invitación-exigencia moral a actuar para mitigar el daño o disminuir el sufrimiento del otro.

Ampliar el nosotros implica, a su vez, tener la certeza de compartir con el otro un peligro común: el dolor y la humillación. Ahora bien, ¿cómo podemos llegar a considerar a quien representa la otredad como uno de nosotros? Este asunto no se desarrolla cabalmente en la propuesta de Rorty, sin embargo, se puede hacer visible una serie de consideraciones generales, al respecto. Así, compartir la certeza del sufrimiento y valorarlo, de tal modo que nos sintamos conminados a actuar para mitigarlo o disminuirlo, supone la puesta en práctica de ciertas valoraciones morales por parte del sujeto: primero, es necesario aprender a juzgar la situación del otro como una situación de sufrimiento, en la forma de dolor o humillación (juicio de reconocimiento del sufrimiento); segundo, ese sufrimiento es susceptible de ser considerado injusto y reprochable (juicio de estimación de la intensidad del sufrimiento); y tercero, se halla en él un peligro que produce alerta frente a la posibilidad de llegar a padecerlo (juicio de las posibilidades parecidas). Rorty (2001, p. 109) insiste en que toda persona moral percibe la posibilidad de llegar a ser humillado y esa percepción lo hermana con quien efectivamente ha estado o está en dicha condición.

2) La solidaridad no se descubre en el fondo de una supuesta o pretendida naturaleza humana y no se funda en un yo nuclear. La solidaridad se crea, se configura en el reconocimiento del sufrimiento del otro, un sufrimiento que yo mismo podría llegar a padecer. De este modo, la solidaridad es la disposición moral a partir de la cual podemos percibir los detalles del dolor y la humillación ajena-nuestra. Tal disposición se orienta hacia la reparación del daño, la evitación del sufrimiento innecesario y la prolongación de una vida digna. La solidaridad, por tanto, no se queda recluida en la emoción o el sentimiento, es, en sentido estricto, 
acción, un tipo de acción que puede contribuir a combatir las desigualdades sociales y a disminuir la indiferencia que se propaga vertiginosamente en el mundo.

3) Por último, y de manera sintética, la solidaridad es el impulso ético que motiva en nosotros la realización de la acción. Este impulso se nutre de la imaginación ética como el lugar de lo posible, de lo que todavía-no-es pero que podría llegar a ser con respecto al otro y a la concreción de un proyecto de vida digno y justo. La imaginación despierta en nosotros el sentido de lo posible para reivindicar el lugar de la experimentación como oportunidad para alcanzar mejores condiciones de vida para los seres humanos. Esta imaginación anima la pretensión de habitar la esfera política y de concebir en ella distintos frentes posibles para la acción. Uno de ellos, tal vez el menos coyuntural de todos, el más estructurado e intencional, es el de la educación, entendida más que como el desarrollo de un oficio o de una actividad profesional, como enseñanza-cuidado del otro, como reivindicación de lo humano en nosotros.

\section{La solidaridad como búsqueda del fundamento último racional y como posibilidad de entendimiento}

En la era de la globalización algunos de los desarrollos de la ciencia y de la tecnología han afectado el horizonte vital de la humanidad. También se han globalizado la explotación y el uso incontrolado del medio ambiente y prevalece la guerra como estrategia de solución de las diferencias en y entre los pueblos. En medio de los desafíos y encrucijadas que esta situación le plantea al hombre contemporáneo, la propuesta de una ética universal advierte acerca de los riesgos de la imposición de la racionalidad estratégica sobre las posibilidades de la racionalidad comunicativa: "Es aquí donde posiblemente pueda hacérsele evidente al científico puro que un acuerdo intersubjetivo metódicamente disciplinado no puede ser substituido por métodos objetivistas de explicación de la conducta o de simulación o manipulación técnica de la misma" (Apel, 1985, p. 138).

Por supuesto, el problema de la fundamentación racional de la ética para los nuevos tiempos exige todo un andamiaje teórico-práctico, desde el cual se postula un universalismo moral sustentado en mínimos morales que guíen los destinos del ser humano y sus actuaciones. Por este camino, Apel reafirma la 
necesidad de construir y mantener nexos entre lo ético y lo político, pues la vida pública ha de ser orientada desde una moralidad pública.

A partir de estas consideraciones, Apel configura, desde lo que denomina arquitectónica de la ética discursiva, una tensión dialéctica entre la fundamentación ética (parte A de esta arquitectónica) y la experiencia cotidiana: las formas de vida reguladas éticamente (parte B). Lo que, en principio, articula ambas partes es la idea de responsabilidad moral. En tal sentido, una ética de este tipo permitiría:

- Pensar en un criterio intersubjetivo de validez moral objetivado en normas.

- Establecer una estrategia moral dirigida a la reconciliación entre la racionalidad comunicativa y la racionalidad estratégica. Así, se considera que el discurso político tiene un alto contenido estratégico, en la medida en que se espera que los implicados y afectados en un conflicto se pongan de acuerdo en los puntos en los que confluyen sus intereses en juego (Ruiz, 2008), en tanto sea posible el reconocimiento de "un criterio de voluntad consensual para todos los implicados, y no solo para los implicados en conflictos" (Apel, 1989, p. 37).
- Diseñar una metodología, un procedimiento, que permita establecer condiciones o principios morales con los cuales dotar de sentido a nuestro actuar y argumentar.

Esta perspectiva de la responsabilidad moral enlaza, al menos, tres prácticas de inaplazable cumplimiento. La primera, se encarga de la fundamentación de las normas a partir de discursos reales, situados históricamente; la segunda, se centra en la orientación moral de la acción a partir del plano normativo fundamentado y susceptible de corrección; y la tercera, tiene como base la búsqueda permanente de consistencia entre fundamentación y acción, entre lo que se acuerda y lo que se realiza, entre lo que se considera justo y lo que se está dispuesto a hacer en consecuencia (Ruiz, 2007).

Así, una concepción de responsabilidad moral se contrapone a la preponderancia que ha alcanzado la racionalidad estratégica en distintas esferas de la vida humana, en particular, en la esfera de la economía: Toda la ambigüedad del
Ilamamiento público a
la responsabilidad po-
lítica puede ser expli-
cado de una vez por la
recomendación dada
por un premio Nobel
de economía [se refiere
Apel a Friedrich Hayek]
de que, en vista de la 
superpoblación de la Tierra, si se quiere reconstruir el equilibrio de la biósfera humana, hay que mantener la situación de desnutrición en los habitantes del tercer mundo (Apel, 1989, pp. 37-38, citado por Ruiz, 2008, p. 60).

De esta manera, las consecuencias del modelo liberal de crecimiento económico desembocan en una suerte de arbitrariedades -dogmatismos con tintes ideológicos- en las que las decisiones que afectan al grueso de la población quedan inmunizadas frente a la crítica y se sitúan al margen de las reflexiones éticas. Está claro que los avances de la razón técnica (instrumental, estratégica) han sido mucho más espectaculares que los de la razón práctica (comunicativa). Sin duda, es preciso extender el radio de acción de la ética al macroámbito de relaciones humanas hacia la comprensión y atención de problemas que afectan a la humanidad en su conjunto (Michelini, 2007).

A juicio de Michelini, el esfuerzo filosófico de Apel se centra en la elaboración de una ética normativa capaz de "demostrar los fundamentos últimos y sentar los criterios básicos que permitan asumir solidariamente la responsabilidad moral por las consecuencias de las acciones humanas en la era de la ciencia" (Michelini, 2007, p. 14). Con más exactitud, Apel trata de demostrar los presupuestos racionales de una normatividad intersubjetivamente vinculante de la responsabilidad humana, que sirva de orientación para las acciones y las decisiones políticas.

Debe resaltarse que la participación de todos los afectados y el proceso de entendimiento mutuo no pretenden la integración homogeneizante o la supresión de las diferencias de los participantes. La idea de responsabilidad se orienta, entonces, al examen de la validez de las exigencias normativas que ellas contienen.

Ahora bien, con respecto al asunto de la solidaridad, y en relación con las dos partes de la arquitectónica de la ética discursiva antes descrita, vale la pena señalar que los sujetos se solidarizan con grupos diversos de la sociedad asumiendo distintos compromisos políticos: "[...] toda persona, en tanto que argumentante, está ya siempre solidarizada transcendentalmente con la comunidad ideal de comunicación" (Michelini, 2007, p. 22, énfasis del original). Esta comunidad ideal de comunicación se presupone más allá de los contextos específicos en los cuales es posible la argumentación (comunidades reales de comunicación) y se constituye en punto de referencia para la vida social y moral. Presuponer la existencia de una comunidad ideal 
anticipa la "hipotética presencia de múltiples comunidades, diversos actores y pluralidad de perspectivas" (Ruiz, 2008, p. 51).

En el nivel de la fundamentación ética (parte A o nivel primordial), los participantes de cara a una comunidad ideal de comunicación interactúan, en principio, en condiciones de simetría, reciprocidad generalizada y total libertad e igualdad. En el nivel situacional y contextual (parte B o esfera performativa), la participación y la comunicación se producen sobre la base de la cooperación y la formación de convicciones comunes -sobre lo considerado bueno, pero, más que todo, sobre lo pretendido justo- en el horizonte del respeto mutuo, el diálogo y la participación sin exclusiones o discriminaciones.

De este modo, puede afirmarse que en el pensamiento filosófico de Apel, la solidaridad está vinculada a la responsabilidad moral o, más precisamente, con un sentido de corresponsabilidad, a la manera de apuesta o visión prospectiva para la sociedad contemporánea, para las instituciones sociales concretas (escuela, trabajo, Estado, entre otras) que requieren de una plataforma normativa en la que se reconozca a todos sus actores, se respete sus diferencias, se pondere y promueva la participación y se creen procedimientos y mecanismos de inclusión.

Los aportes de Apel en la comprensión contemporánea de la solidaridad se pueden sintetizar así: en primer lugar, la solidaridad en el nivel primordial (fundamentación) no está referida únicamente a la formulación de una idea regulativa que oriente las acciones humanas -como aquella instancia trascendental que fundamenta todas las acciones solidarias-, sino que se convierte en un criterio de orientación de una condición concreta (en el nivel situacional o contextual) de búsqueda de consistencia moral (Ruiz, 2008, p. 55). Considerar a la solidaridad parámetro crítico para la búsqueda de consistencia moral representa el esfuerzo de los grupos sociales por identificar posibles inconsistencias en su actuar y por encontrar los argumentos que puedan impulsar la puesta en escena de acciones solidarias entre los miembros de la comunidad real de comunicación.

En segundo lugar, desde la ética discursiva, la respuesta a la pregunta ¿por qué ser solidario? implica recurrir a una fundamentación racional sustentada en un proceso de reflexión pragmático-trascendental. Lo pragmático, habíamos sostenido en otro contexto de discusión, tiene que ver con "las condiciones lingüístico-argumentativas manifiestas en el mundo de todos los días, en el que más allá de la posibilidad de expresar o no verdades proposicionales, las personas comunican los significados de su acción, sus sentimientos, intenciones y anhelos" (Ruiz, 2008, p. 43). Mientras que lo trascendental se define en un plano normativo, más allá de los contextos situacionales concretos, por lo que 
podría considerarse que tendría una "justeza y una legitimidad universal" (Ruiz, 2008, p. 43). Ser solidario coincidiría, en suma, con las presuposiciones normativas inherentes a la argumentación de los miembros de una comunidad ideal de comunicación. La solidaridad es, entonces, una pretensión que mueve a la acción. Reconocer la existencia de la ley moral nos haría, por tanto, tener que reconocer que somos corresponsables solidariamente con todos los miembros de dicha comunidad (sujetos de otras culturas y formas de vida e, incluso, con quienes aún no han nacido o que habiendo habitado el pasado requieren ser reconocidos y reivindicados). Aquí queda ya situada la respuesta a la pregunta ¿con quién ser solidario? Se es solidario, o mejor sería decir, se debe ser solidario con los miembros de esta comunidad extendida e ilimitada de argumentantes potenciales o reales.

En tercer lugar, la corresponsabilidad solidaria es un fenómeno moral en el que los seres racionales son considerados lingüística y comunicativamente competentes (Michelini, 2007). La solidaridad, en estos términos, supone la puesta en consideración de esas habilidades comunicativas y argumentativas de los seres humanos, como posibilidad de cooperación para la resolución de problemas prácticos, pero, sobre todo, para alcanzar el entendimiento mutuo (Ruiz, 2012).

\section{La solidaridad como estimación social y reconocimiento de singularidades}

Para abordar la solidaridad desde la teoría del reconocimiento, Honneth recurre a Hegel, quien, a su vez, hizo un importante esfuerzo para reinterpretar y superar la idea del contrato social de Hobbes e introdujo una nueva concepción de lucha social, más allá del interés por la autoconservación física, desencadenada por la búsqueda del reconocimiento recíproco y la confirmación de la identidad de la persona singular en la vida social. Para este pensador, la lucha va más allá de la autoconservación de los sujetos, de modo tal que los conflictos están asociados a motivos morales. Tal lucha se origina en la búsqueda de formas ampliadas de reconocimiento recíproco del orden institucional y cultural, orientada por el interés de ampliar las bases sobre las que se establecen las relaciones sociales: si no reconozco al otro en la interacción, no estarán dadas las condiciones emocionales, cognitivas y morales a partir de las cuales quiero ser confirmado por él. Así pues, mi existencia está ligada a la existencia 
del otro, quien confirma e interpela de manera permanente mi presencia en el mundo.

De este modo, la lucha resulta ser el motor de los cambios sociales, en la que los sujetos "ininterrumpidamente tratan de ensanchar el perímetro de los derechos que se les conceden intersubjetivamente para elevar el grado de su autonomía personal" (Honneth, 1997, p. 160). Se trata, por tanto, de un movimiento de reconocimiento que consiste en un proceso permanente de conflictoreconciliación. En este movimiento, los sujetos deben abandonar y superar las relaciones éticas en que originariamente se encontraban, sobre todo cuando no logran sentir reconocida del todo su identidad particular en el grupo social del que forman parte. Si bien la lucha ya no es por la autoconservación física, como lo era en la concepción hobessiana, sobre el estado de naturaleza, sí lo es por el reconocimiento intersubjetivo al que se ve abocado la individualidad humana.

Se vislumbran, entonces, rasgos comunitarios en esta perspectiva del reconocimiento, que aquí son asumidos como potenciales morales, propios de una eticidad natural, rasgos que si bien son "encubiertos y no desarrollados" forman parte del movimiento generado por los conflictos y las posteriores reconciliaciones y devienen en condición de posibilidad, en referentes éticos con los cuales una sociedad acuerda las relaciones de interacción, para el reconocimiento recíproco entre sus miembros o por la conformación de "una forma de sociedad que encuentre su conexión orgánica en el reconocimiento intersubjetivo de la particularidad de todos los singulares" (Honneth, 1997, p. 26).

La lucha sucede en movimientos éticos de menor a mayor madurez y en ella los sujetos encuentran condiciones cada vez más propicias y favorables para el desarrollo y la expansión de su potencial moral, el mismo que pasa del reconocimiento de sus propias capacidades y potencialidades (reconocimiento de sí mismos basado en la confianza), al reconocimiento de las capacidades y potencialidades de los otros (reconocimiento recíproco). De esta manera, la lucha social ha de ampliar los márgenes de valoración que surgen entre los sujetos que habitan un tiempo y un espacio determinado. Así pues, la lucha es sinónimo de una búsqueda que los seres humanos despliegan para insertarse en relaciones éticas más simétricas, en las que generan sentimientos de confianza, respeto y valoración social de sí mismo y de los otros.

Desde la perspectiva hegeliana en la que se apoya Honneth se distinguen tres estadios del reconocimiento recíproco: el amor, cuyo principio es encarnado por la atención amorosa y su representación institucional es la familia; el derecho, que se basa en el principio del reconocimiento jurídico y su representación institucional es la sociedad civil; y la solidaridad, cuyo principio es la adhesión solidaria y 
su representación institucional es el Estado. Estas tres moda-lidades de reconocimiento conllevan un concepto de persona, en el sentido de que en cada una de ellas crece la autonomía particular de los sujetos, así como "crece progresivamente el grado de relación positiva de la persona consigo misma" (Honneth, 1997, p. 116). A su vez, cada modalidad remite a formas diferenciadas de reconocimiento recíproco, a las que les corresponde un potencial diferente de desarrollo moral y tipos diversos de autorreferencia individual. Cada una de ellas encuentra, a su vez, su equivalente en el menosprecio o no-reconocimiento, que causan heridas profundas a la subjetividad e influye determinantemente en las relaciones intersubjetivas.

Es precisamente en el amor, en el que los sujetos confirman su naturaleza necesitada y su condición de entes de necesidad. En la relación amorosa existe una experiencia unificada de recíproco reconocimiento, en cuanto las personas concernidas en relaciones amorosas se saben necesitadas del afecto que el otro puede brindarles. En la relación de amor, como experiencia primaria de reconocimiento recíproco, nos percibimos como "ser-sí-mismo-en-otro". Esta consideración de ser sí mismos configurada en la experiencia de ser-en-otros (o sercon-otros) favorece el avance hacia posibilidades de reconocimiento de la autonomía, la diferencia y la singularidad. Esta modalidad de reconocimiento recíproco es fundamental para las otras modalidades, en la medida en que si el sujeto no se reconoce como ente autónomo, portador de derechos, no puede, ni podrá reconocer el conjunto de obligaciones normativas que tiene para con los otros ocasionales en el decurso de la vida social. El prototipo empírico que mejor encarna este momento es la relación entre madre e hijo(a). El equivalente en el menosprecio se corresponde con el maltrato físico y la violación, entendidas como aquellas formas de violencia en las que a una persona le son retiradas por la fuerza todas las posibilidades de libre disposición sobre su cuerpo, lo cual representa la manera más primitiva de humillación personal. Pero solo es en y por el derecho, que el sujeto es tratado y reconocido por el Estado, de este modo:

[...] como ser racional, como libre, como persona y como individuo singular [y es en el derecho que] se hace digno de reconocimiento porque obedece, al superar la naturalidad de su conciencia de sí, a un universo, 
a la voluntad que es en

y para sí, la ley -que se

comporta así frente a

los otros de una manera

universalmente válida-,

porque los reconoce

como aquello por lo que

él mismo quiere pasar,

como libres, como per-

sonas (Honneth, 1997,

p. 133).

Solo en la perspectiva normativa de un "otro generalizado" podemos entendernos a nosotros mismos como personas de derechos, en la medida en que podemos estar seguros de la realización social de algunas de nuestras pretensiones. En un sentido jurídico, el reconocimiento aborda dos cuestiones: la ampliación de la esfera de los derechos reconocidos a las personas y el enriquecimiento de las capacidades que estos sujetos se reconocen entre sí. La forma de menosprecio en este nivel es la desposesión de derechos y la exclusión social que afecta la autocomprensión normativa del sujeto.

Finalmente, corresponde a la solidaridad, entendida como "intuición recíproca" la posibilidad de que el individuo "se intuya" a sí mismo en cada uno de los demás seres humanos. Al respecto, Honneth destaca que Hegel intentó definir una forma reflexiva de relaciones recíprocas entre sujetos que va más allá del reconocimiento cognitivo:

Ese modelo de reconocimiento, que incluye lo afectivo, para el que pronto se apresta la categoría de solidaridad, debe proporcionar claramente la base comunicativa sobre la cual los individuos, aislados unos de otros por las relaciones jurídicas, pueden volver a encontrarse en el marco global de una comunidad ética (Honneth, 1997, p. 37).

Los equivalentes como experiencia de menosprecio aquí son la injuria y la indiferencia, las cuales desvirtúan los modos de vida individuales y colectivos.

En el planteamiento hegeliano original, la solidaridad articula las otras dos formas de reconocimiento: el derecho, porque comparte el punto de vista cognitivo del tratamiento igualitario; y el amor, porque prevalece en las relaciones la conexión emocional y la atención amorosa. Así, se consolidan relaciones sociales en las cuales, cuando el amor surge, ante la presión cognitiva del derecho, se purifican las relaciones "hacia una solidaridad universal entre los miembros de la comunidad. Porque en esta implantación cada sujeto puede respetar al otro en su especificidad individual; en ella se cumple la forma de reconocimiento más plena de pretensiones" (Honneth, 1997, p. 13). En este sentido, la solidaridad se concibe como objetivo ético en el marco de sociedades plurales constituidas por 
seres humanos que establecen o se esfuerzan por establecer relaciones simétricas con los demás miembros de la sociedad.

Así, la solidaridad se asocia a la experiencia de valoración social -o estima social- en la medida en que resume todas las modalidades del reconocimiento recíproco, yendo más allá del reconocimiento de la igualdad de derechos entre sujetos libres. Tal forma de valoración social se concibe, a su vez, como la estima de determinadas cualidades de la persona que pueden servir como marco de orientación de la acción. Su valor reside en la capacidad de contribuir a la realización de los propósitos de la sociedad. De este modo, la sociedad y sus miembros proporcionan "los criterios según los que se orienta la valoración social de las personas, porque sus capacidades y actuaciones pueden ser intersubjetivamente estimadas en la medida [en que] cooperan en la realización de valores socialmente definidos" (Honneth, 1997, p. 150).

Sin embargo, las cualidades personales no son aquellas pertenecientes a sujetos individualizados, sino las culturalmente reconocidas y estimadas por el grupo social de referencia. Su valor reside en la contribución que hacen a la realización de los objetivos sociales, a partir de la cual también se mide el valor social de cada uno de sus miembros. La atribución de valor a los miembros estaría relacionada con sus participaciones "activas" en la realización de los propósitos socialmente trazados y compartidos. Por tanto, la valoración o la estima podrían considerarse como un tipo de recompensa social (honorabilidad, prestigio) atribuida por el grupo social del cual se forma parte.

Si cada uno de los sujetos se sabe valorado por los otros en la misma medida, estas relaciones adoptan el carácter de solidarias. Honneth destaca, así, que para Hegel la solidaridad significa "un tipo de relación de interacción en el que los sujetos recíprocamente participan en sus vidas diferenciables, porque se valoran entre sí en forma simétrica" (Honneth, 1997, p. 157). En estos términos, valorarse simétricamente significa considerarse incluido y reconocido en el horizonte de valores sociales que hacen aparecer las capacidades y las cualidades de sus miembros como significativas para la praxis común. Así, este tipo de relaciones se entienden como solidarias

Porque no sólo despiertan tolerancia pasiva, sino participación activa en la particularidad individual de las otras personas; pues sólo en la medida en que yo activamente me preocupo por que el otro pueda desarrollar 
cualidades que me son extrañas, pueden realizarse los objetivos que nos son comunes (Honneth, 1997, p. 159).

A modo de síntesis, puede decirse que desde esta perspectiva la solidaridad es un tipo de relación pretendidamente recíproca en la que participan sujetos que se valoran simétricamente y se desarrollan cualidades y capacidades significativas para el grupo social del cual forman parte. Esta relación surge bajo la consideración de un momento de desarrollo moral más maduro y sensible al proyecto de vida de los otros con quienes se comparte una historia común.

Finalmente, la solidaridad también implica la participación recíproca de los sujetos en los objetivos y las pretensiones que cada uno se ha trazado de manera individual, como parte, también, de un proyecto de vida común. Esta perspectiva filosófica representa, en suma, la posibilidad de situar y comprender la solidaridad en el marco de las relaciones recíprocas basadas en la simetría y en la horizontalidad, con una base comunicativa, en un horizonte de valores sociales que hacen aparecer las capacidades de las personas como significativas para la vida en común, para la construcción de proyectos de vida compartida.

\section{Encuentro de perspectivas y consideraciones finales}

Recapitulando, en la primera de las concepciones presentadas la solidaridad se refiere a algo que nos impulsa a ampliar nuestro círculo éti$C O$, en respuesta a la crueldad humana, que es lo peor que puede existir en el mundo (Rorty); en la segunda damos cuenta de la solidaridad en relación con la idea de responsabilidad, lo cual exige el examen de la validez de las exigencias normativas en la comunicación y plantea como indispensable la participación de todos los afectados en una situación social dada (Apel). En la tercera, la solidaridad es una disposición hacia el otro, hacia quien nos interpela, lo que, a la vez, se traduce en demandas y acciones de reconocimiento (Honneth).

Hemos visto, así, que el abordaje de la solidaridad como concepto filosófico enfatiza en la valoración y el reconocimiento de las singularidades del otro, así como en la posibilidad de construcción de proyectos comunes justos e incluyentes. En esta misma línea argumental, las perspectivas expuestas coinciden en entender a la solidaridad como respuesta moral ante el sufrimiento del otro, en consideración de las diferencias culturales, sociales, económicas y políticas entre individuos y entre grupos sociales.

Más allá de las divergencias que estas perspectivas tengan acerca 
de la solidaridad pueden señalarse una serie de coincidencias, convergencias y derivaciones conceptuales, bien como escenario de posibilidad, por medio de la imaginación sociológica y moral, bien como territorio para la reivindicación de derechos, mediante los cuales se busca promover la justicia y la igualdad de oportunidades. De este modo:

La solidaridad encuentra un importante asiento en el estímulo de la imaginación (sociológica y moral), que permite que las personas nos ubiquemos hipotéticamente en el lugar del otro, de quien sufre, lo que para Martuccelli (2007) representa la base de una hermenéutica de la alteridad. Tal imaginación implica, a su vez, una ampliación simbólica e indefinida del círculo ético, a partir de la cual es posible el reconocimiento del otro y la promoción de acciones colectivas orientadas a la disminución de la desigualdad social. La solidaridad así entendida

Consiste en desarrollar una imaginación ética que opere como fuerza humanizadora y nutriente de un sentido inclusivo de justicia. Se hace necesaria la disposición solidaria que nos prepare para atisbar los cambios que nos puedan conducir a una disminución de la desigualdad en el mundo (Figueroa, 2007, p. 196).

La imaginación moral opera aquí como sensibilidad moral articulable a la reflexión racional, como ampliación de las fronteras de lo humano: "[...] incrementando nuestra sensibilidad a los detalles particulares del dolor y de la humillación de seres humanos distintos, desconocidos para nosotros. Una sensibilidad incrementada hace más difícil marginar a personas distintas a nosotros" (2001, p. 18). A su vez, dicha sensibilidad supone que hay algo que resuena en nosotros frente a la evidencia de algo que nos es común con otros, razón por la cual podemos llegar a sentirnos responsables moralmente de los demás.

De ahí que la solidaridad pueda considerarse una disposición moral ante cualquiera que sufre dolor y humillación, sin importar de quien se trate. Esta disposición hace que resuene en nosotros algo que nos permite percibir daño en el otro y nos invita a actuar para mitigarlo o para evitar o disminuir su sufrimiento.

La solidaridad supone, igualmente, la existencia de un vínculo, de una unión hipotética, incluso entre seres humanos lejanos y distantes cultural o geográficamente. Así las cosas, la solidaridad enlaza una proximidad (proxĭmĭtas), que trasciende lo social, una proximidad moral, que se desarrolla en razón de la 
cercanía o similaridad de las experiencias ante el dolor y el sufrimiento de los seres humanos.

La solidaridad también requiere la creación o re-creación de nuevos lenguajes y de analogías para renovar los sentidos de lo humano y respetar la singularidad que el otro encarna. Al respecto, Rorty (2001, 40), en particular, recurre a la idea de léxico último como "[...] un cambio en la forma de hablar y, con ello, un cambio de lo que queremos hacer y de lo que pensamos que somos". Por su parte, Martuccelli (2007) recurre a la analogía en la comprensión de la solidaridad, entendiendo aquella como el mecanismo intelectual a través de cual se pueden crear otros lenguajes que sean capaces de informar de otra manera las mismas situaciones. Mediante este recurso, entonces, es posible introducir preguntas indiscretas, inesperadas e incómodas o establecer resonancias imprevistas para cuestionar los comportamientos y acciones solidarias. En suma, usar el lenguaje de otra manera sugiere virar hacia otras posibilidades y gestar otras oportunidades.

Vale destacar que la solidaridad surge a partir del reconocimiento del otro, de sus singularidades y potencialidades para ser y actuar en el mundo. Bien sea en respuesta al sufrimiento de los seres humanos o a las exigencias de aferrarse a vivir una vida auténtica (Taylor, 1994), así, la solidaridad expresa un modo de disposición hacia los demás: nos conmina a un sentido de responsabilidad hacia, por y con el otro, que se traducen en requerimientos de acción.

La solidaridad está, por tanto, estrechamente vinculada a la justicia, lo está en dos sentidos, primero, en la medida en que la justicia le ofrece un fundamento y una guía moral y, segundo, porque la justicia le permite vislumbrar un horizonte de sentido para la acción concreta. De esta manera, el discurso filosófiCO, contra-fáctico, sobre la solidaridad plantea enormes retos prácticos para nuestra sociedad actual y, a nuestro juicio, enlaza la necesidad del desarrollo de estudios empíricos, desde las ciencias sociales aplicadas y desde el campo de la educación que permitan una comprensión más amplia y situada de las formas como se ejerce, se vive, se demanda y se anhela la solidaridad en la vida de todos los días. Esperamos, así, que esta indagación y caracterización teórica sobre la solidaridad aporte algunos elementos conceptuales de apoyo a los desarrollos ulteriores señalados.

\section{Referencias bibliográficas}

Apel, K.-O. (1985). La transformación de la filosofía (Tomo II. El a priori de la comunidad de comunicación). Madrid: Taurus.

Apel, K.-O. (1989). La situación del hombre como problema ético. En X. Palacios y F. Jarauta (eds.), Razón, ética y política. Barcelona: Anthropos.

Astorga, O., y Kohn, C., (2001). El liberalismo y la solidaridad: ¿son 
conmensurables? Revista Internacional de Filosofía Política, (18), 139-153.

Figueroa, M. (2007). Richard Rorty: idea y construcción pragmatista de la solidaridad. En M. Figueroa y D. Michelini (comps.), Filosofía y solidaridad: estudios sobre Apel, Rawls, Ricoeur, Lévinas, Dussel, Derrida, Rorty y Van Parijs. Santiago de Chile: Universidad Alberto Hurtado.

Honneth, A. (1997). La lucha por el reconocimiento. Por una gramática moral de los conflictos sociales. Barcelona: Grijalbo.

Honneth, A. (2009). Crítica del agravio moral: patologías de la sociedad contemporánea. Buenos Aires: F.C.E.

Nussbaum, M. (1997). Justicia poética. Santiago de Chile: Andrés Bello.

Nussbaum, M. (2011). Sin fines de lucro. Por qué la democracia necesita de las humanidades. Buenos Aires: Katz.

Martuccelli, D. (2007). Cambio de rumbo. La sociedad a escala del individuo. Santiago: Lom.

Mardones, J. M. (1994). Por una cultura solidaria: actitudes ante la crisis. Madrid: Sal Terrae.

Michelini, D. (2007). Discurso y solidaridad en Karl-Otto Apel. En M. Figueroa y D. Michelini (comps.). Filosofía y solidaridad: estudios sobre Apel, Rawls, Ricoeur, Lévinas, Dussel, Derrida, Rorty y Van Parijs. Santiago de Chile: Universidad Alberto Hurtado.

Rorty, R. (2000). Verdad y progreso. Barcelona: Paidós.

Rorty, R. (2001). Contingencia, ironía y solidaridad. Barcelona: Paidós.

Rorty, R. (2005). Filosofía y futuro. Barcelona: Gedisa.

Ruiz, A. (2007). El diálogo como acción comunicativa. En G. Schujman (coord.), Filosofía. Temas fundamentales y aportes para su enseñanza. Buenos Aires: Biblos.

Ruiz, A. (2008). El diálogo que somos: ética discursiva y educación. Bogotá: Magisterio.

Ruiz, A. (2012). Un diálogo infinito. Pedagogía y Saberes, 36, 71-80.

Taylor, Ch. (1994). La ética de la autenticidad. Barcelona: Paidós. 